\title{
Knowledge, attitudes and practices regarding rabies risk in community members and healthcare professionals: Pétionville, Haiti, 2013
}

\author{
N. FENELON ${ }^{1}$, P. DELY ${ }^{1}$, M. A. KATZ ${ }^{2}$, N. D. SCHAAD ${ }^{2}$, A. DISMER $^{2}$, \\ D. MORAN ${ }^{3}$, F. LARAQUE ${ }^{2}$ AND R. M. WALLACE ${ }^{4 *}$ \\ ${ }^{1}$ Department of Epidemiology and Laboratory Research, Port-au-Prince, Haiti \\ ${ }^{2}$ Centers for Disease Control and Prevention, Health Reconstruction Team, Port-au-Prince, Haiti \\ ${ }^{3}$ Center for Health Studies, Universidad del Valle de Guatemala, Guatemala City, Guatemala \\ ${ }^{4}$ Centers for Disease Control and Prevention, Division of High-Consequence Pathogens and Pathology, Atlanta, \\ GA, USA
}

Received 25 May 2016; Final revision 15 September 2016; Accepted 1 November 2016; first published online 14 March 2017

\section{SUMMARY}

Haiti has the highest human rabies burden in the Western Hemisphere. There is no published literature describing the public's perceptions of rabies in Haiti, information that is critical to developing effective interventions and government policies. We conducted a knowledge, attitudes and practices survey of 550 community members and 116 health professionals in Pétionville, Haiti in 2013 to understand the perception of rabies in these populations. The majority of respondents $(85 \%)$ knew that dogs were the primary reservoir for rabies, yet only $1 \%$ were aware that bats and mongooses could transmit rabies. Animal bites were recognized as a mechanism of rabies transmission by $77 \%$ of the population and $76 \%$ were aware that the disease could be prevented by vaccination. Of 172 persons reporting a bite, only $37 \%$ sought medical treatment. The annual bite incidence rate in respondents was $0.9 \%$. Only $31 \%$ of bite victims reported that they started the rabies vaccination series. Only $38 \%$ of respondents reported that their dog had been vaccinated against rabies. The majority of medical professionals recognized that dogs were the main reservoir for rabies (98\%), but only $28 \%$ reported bats and $14 \%$ reported mongooses as posing a risk for rabies infection. Bites were reported as a mechanism of rabies transmission by $73 \%$ of respondents; exposure to saliva was reported by $20 \%$. Thirty-four percent of medical professionals reported they would wash a bite wound with soap and water and $2 \cdot 8 \%$ specifically mentioned rabies vaccination as a component of post-bite treatment. The majority of healthcare professionals recommended some form of rabies assessment for biting animals; $68 \cdot 9 \%$ recommended a 14-day observation period, $60 \cdot 4 \%$ recommended a veterinary consultation, and $13.2 \%$ recommended checking the vaccination status of the animal. Fewer than $15 \%$ of healthcare professionals had ever received training on rabies prevention and $77 \%$ did not know where to go to procure rabies vaccine for bite victims. Both study populations had a high level of knowledge about the primary reservoir for rabies and the mode of transmission. However, there is a need to improve the level of knowledge regarding the importance of seeking medical care for dog bites and additional training on rabies prevention for healthcare professionals. Distribution channels for rabies vaccines should be evaluated, as the majority of healthcare providers did not

\footnotetext{
* Author for correspondence: R. M. Wallace, DVM, MPH, 1600 Clifton Road, MS G-43, Atlanta, GA 30333, USA. (Email: EUK5@cdc.gov)

This is an Open Access article, distributed under the terms of the Creative Commons Attribution licence (http://creativecommons.org/licenses/by/4.0/), which permits unrestricted re-use, distribution, and reproduction in any medium, provided the original work is properly cited.
} 
know where rabies vaccines could be obtained. Canine rabies vaccination is the primary intervention for rabies control programmes, yet most owned dogs in this population were not vaccinated.

Key words: Dog bites, Haiti, rabies, socioeconomic.

\section{INTRODUCTION}

Rabies virus, a neurotropic lyssavirus which causes an invariably fatal encephalitis, affects more than 150 countries and territories [1]. Each year over 59000 people die of rabies worldwide; which represents 160 deaths per day [2]. Rabies virus has differentiated into numerous variants, each associated with specific mammalian hosts. However, the viral variant associated with dogs is responsible for $99 \%$ of human rabies deaths worldwide. Many countries have recently made strides to eliminate the canine variant, and in 1983, the Pan American Health Organization (PAHO) launched a regional programme against rabies which has markedly reduced the incidence of human and canine rabies deaths in the Western Hemisphere [3]. Through the success of initiatives like those of PAHO, there are now only four countries in the Western Hemisphere that persistently record human deaths due to canine rabies virus: Haiti, Dominican Republic, Guatemala, and Bolivia.

In the Republic of Haiti, a Caribbean island nation of 10.5 million people, canine rabies virus variant remains a serious public health problem. An estimated 130 human deaths from rabies occur in the country each year [2]. Unfortunately, due to limitations in healthcare provider recognition, surveillance, and diagnostic capacity, only a fraction of these deaths are recognized [4]. The majority of recognized human rabies deaths and animal bite events have been reported from the West Department, which includes the capital city, Port-au-Prince. Almost all of these human deaths and bite events are due to domestic dogs; however, few successful preventive measures have been implemented due to lack of resources [4]. Haiti has an estimated 750000 dogs according to a 2007 census, yet between 2009 and 2010, an average of only 214627 dogs were vaccinated (annual vaccination rate of $28.6 \%$ ).

A foundational component of a successful rabies programme is the formation of a well-educated population in regards to rabies risks and control of this disease [5]. Currently, no published studies have described the knowledge, attitudes and practices of rabies prevention in community members and healthcare professionals (HCPs) in Haiti. The Haitian Ministry of Health (MSPP) and US Centers for Disease Control and Prevention (CDC) conducted a community survey to better understand the risk of rabies exposure in Haiti, post-bite healthcare-seeking behaviours, and barriers to appropriate care.

\section{METHODS}

A knowledge, attitudes, and practices survey was conducted in January-May 2013 (see Supplementary Appendix). Surveys were conducted in two populations within the commune of Pétionville: community members and HCPs. Pétionville had 359956 inhabitants according to the National Institute of Statistics and Information (IHSI)'s 2012 estimates and is an urban community within the capital city Portau-Prince. The Pétionville population has an aboveaverage socioeconomic status [6]. Prior to conducting the survey, investigators held an orientation session for interviewers on the use of the questionnaire and consent form. Each questionnaire consisted of 47 (HCP) and 41 (community member) questions which were divided into five sections: Socio-demographic, Rabies knowledge, Attitudes towards animal bites, and Bite treatment practices. Surveys were conducted in Creole, Haiti's official language. Respondents were read questions, but were not provided answers from which to choose. Open-ended questions allowed for multiple responses.

\section{Community members}

For the community survey a confidence level of $95 \%$ (1.96), a margin of error of $5 \%(0.05)$, a populationlevel knowledge of rabies estimated at 50\% (because the proportion with knowledge of rabies was not known) $(0.5)$ and design effect (1.5) were chosen to calculate the desired sample size: 576 participants. The sample size was increased by $20 \%$ to account for persons not eligible to participate due to age, absence from home or refusal to participate. A total sample 
size of 720 participants was determined necessary to detect statistically significant differences in responses.

A two-stage cluster sampling method was used utilized. Pétionville is administratively subdivided into 313 enumeration areas (EAs) by IHSI. Thirty (10\%) EAs were randomly selected using the population proportionate-to-size method [7]. The quotient of 720 participants and 30 EAs was used to determine that 24 households were required from each cluster. In the 30 selected EAs, surveyors created an exhaustive list of all households using the continuous path of travel methodology to ensure that all households were included in the sample [7]. A random number generator was then used to randomly select 24 households from the list within the cluster. Each interviewer used a Global Positioning System unit to verify the boundaries of the cluster and to ensure that the correct houses were surveyed. Heads of households were requested for the interview; however, any willing participants aged $\geqslant 18$ years were eligible (one person interviewed per household).

\section{HCPs}

For the survey of HCPs, we accessed a health facility registry for Pétionville, maintained by MSPP, to identify institutions eligible for the survey. Eligible health centres had either emergency outpatient, internal medicine or paediatric services. Forty-eight eligible facilities were identified. Health facilities were visited by interviewers on two consecutive days to recruit participants. Convenience sampling was conducted at all selected health facilities, with any doctor or nurse providing consent eligible for entry.

\section{Data collection and analysis}

Two databases were created in Epi-Info v. 3.5.3 (CDC, USA) for data analysis with respect to the two study populations. Univariate analysis of frequency, rates, and means were calculated. Lifetime animal bite incidence was calculated as the number of primary bites that community participants reported receiving divided by the number of people surveyed. The annual bite incidence for the study population was determined by dividing the number of primary bites by the life-years represented in the study, which was calculated for each stratified age group. Respondents' exact age was not collected, rather they were classified in an age group, and life-years were calculated as the product of the median age within each age group and the number of participants within the respective group.

\section{Ethical considerations}

All study participants were aged $\geqslant 18$ years and signed a consent form. The study was approved by the Haiti Ethics Committee of the Haitian Ministry of Health (FWA 00016848) and the US CDC deemed the activity as non-research.

\section{RESULTS}

\section{Community members}

Of 720 individuals selected, 550 agreed to participate (response rate $76 \cdot 3 \%$ ). The average age of respondents was 35 (range 18-90) years (Table 1). There were more female respondents $(56.5 \%)$ than males, and most respondents $(71.5 \%)$ had at least secondary school education. Overall, $24 \%$ of respondents were unemployed, $22 \%$ were merchants, $13.8 \%$ were students, and the remaining reported other forms of employment. The annual median household income of the study population was 4274 USD, compared to a national median of 1800 USD. Pet ownership was documented for 229 respondents $(41.6 \%)$, for which 453 pets were recorded. Dogs were more commonly owned $(n=239)$ than cats $(n=214)$. Of the 239 owned dogs, $91 \quad(38 \cdot 1 \%)$ had reportedly been vaccinated against rabies.

The majority, $85 \%$ (468), of respondents correctly reported that the primary rabies reservoir in Haiti was dogs (Table 2). Only 29.6\% (163) reported cats as a vehicle of transmission, and only $1.5 \%$ were aware that bats or mongooses can also transmit rabies virus. Most respondents $(75 \cdot 6 \%)$ reported bites as a method of rabies virus transmission. One in five respondents reported that they were not aware of how rabies was transmitted. Regarding the prevention of disease, $71 \cdot 6 \%$ (394) of respondents answered that rabies was a preventable disease through post-bite vaccination, and $79 \cdot 5 \%$ (437) reported that vaccination of dogs and cats was an important strategy to reduce the transmission of rabies in humans. Nine out of ten respondents did not know where to go to receive rabies vaccination following an animal bite. Over half of respondents $(54 \cdot 7 \%)$ thought that rabies could be treated, even after symptom onset.

Overall $46 \%$ of respondents indicated that if they were bitten by a suspected rabid animal, they would kill the animal, and only 13\% reported that they 
Table 1. Demographics of community members participating in a rabies knowledge, attitudes, and practices survey, Pétionville, Haiti, 2013

\begin{tabular}{|c|c|c|c|c|c|c|}
\hline \multicolumn{3}{|c|}{ Community members $(N=550)$} & \multicolumn{3}{|c|}{ Healthcare professionals $(N=160)$} & \multirow{2}{*}{$\begin{array}{l}\text { Haiti National } \\
\text { Statistics* }\end{array}$} \\
\hline & $N$ & $\%$ & & $N$ & $\%$ & \\
\hline $\begin{array}{l}\text { Median age, years } \\
\text { (range) }\end{array}$ & $35(18-90)$ & - & $\begin{array}{l}\text { Median age, years } \\
\text { (range) }\end{array}$ & $37(23-72)$ & - & 22.5 years \\
\hline $\begin{array}{l}\text { Median annual } \\
\text { household income } \\
\text { (range) }\end{array}$ & $\begin{array}{l}4274 \text { USD } \\
(1200-14400)\end{array}$ & - & & - & - & 1800 USD \\
\hline \multicolumn{7}{|l|}{ Sex } \\
\hline Male & 239 & $43 \cdot 5$ & Male & 15 & $14 \cdot 2$ & $50 \cdot 1 \%$ \\
\hline Female & 311 & $56 \cdot 5$ & Female & 91 & $85 \cdot 8$ & $49 \cdot 9 \%$ \\
\hline \multicolumn{7}{|l|}{ Education } \\
\hline Illiterate & 50 & $9 \cdot 1$ & & - & - & $\begin{array}{l}22 \% \text { of Haitians have a } \\
\text { secondary degree or higher }\end{array}$ \\
\hline Primary school & 102 & $18 \cdot 5$ & & - & - & \\
\hline Secondary school & 318 & $57 \cdot 8$ & & - & - & \\
\hline University & 75 & $13 \cdot 6$ & & - & - & \\
\hline No response & 5 & $0 \cdot 9$ & & - & - & \\
\hline \multicolumn{7}{|l|}{ Occupation } \\
\hline Unemployed & 132 & $24 \cdot 0$ & Nurse & 72 & $67 \cdot 9$ & - \\
\hline Professor & 20 & $3 \cdot 6$ & Doctor - social services & 3 & $2 \cdot 8$ & \\
\hline Student & 76 & $13 \cdot 8$ & Doctor-general practice & 18 & $17 \cdot 0$ & \\
\hline Merchant & 123 & $22 \cdot 4$ & Doctor - specialist & 13 & $12 \cdot 3$ & \\
\hline Other employment & 199 & $36 \cdot 2$ & & - & - & \\
\hline \multicolumn{7}{|c|}{ Households owning pets } \\
\hline Yes & 229 & $41 \cdot 6$ & Yes & 51 & $48 \cdot 1$ & - \\
\hline Number of dogs & 239 & - & Number of dogs & 51 & & \\
\hline Rabies vaccinated & 91 & $38 \cdot 1 \dagger$ & Rabies vaccinated & 13 & $25 \cdot 5 \dagger$ & \\
\hline Number cats & 214 & - & Number cats & 0 & & \\
\hline No & 321 & $58 \cdot 4$ & No & 55 & $51 \cdot 9$ & \\
\hline
\end{tabular}

* Source: World Fact Book [6].

$\dagger$ Percentage calculated as the quotient of rabies-vaccinated dogs and the total number of dogs owned by the survey respondents.

would take the offending animal to a veterinarian (Table 3). Very few respondents $(8 \%)$ indicated that they would monitor the biting animal for signs of rabies. However, of the 172 persons $(31 \cdot 3 \%$ of total) who reported having had an animal bite in their lifetime, $80 \%$ said they did nothing with the offending animal, $16.3 \%$ said they killed the animal, and $8.7 \%$ said they observed the animal for 14 days. When asked what they would do if they were bitten by an animal suspected of having rabies, $90.7 \%$ said they would seek care at a clinic or hospital, $6 \%$ said they would wash the wound with soap and water, and $4 \cdot 1 \%$ indicated they would do nothing or they did not know what they would do. No one reported that they would seek care from a traditional healer. Of the 172 bite victims captured in this survey, only $36 \cdot 6 \%$ sought treatment at a clinic or hospital, and $8.1 \%$ washed the wound with soap and water. Over
$36 \%$ of bite victims stated that they did nothing to treat the wound, and $3 \cdot 5 \%$ of bite victims sought help from a traditional healer. Only $31.4 \%$ of bite victims said that they initiated the rabies vaccination series.

A total of 19114 life-years are represented in this survey, of which 172 people indicated that they had experienced at least one animal bite (minimum annual bite incidence rate of $0.9 \%$ ) (Table 4 ). The highest annual bite rate was seen in the 18-29 years age group (1.3 bites/100 life-years). The lowest bite rate was observed in persons aged $\geqslant 60$ years $(0.13$ bites/ 100 life-years). Dogs were the most frequently reported offending animal, responsible for $93.6 \%$ of bite events (Table 5). Of those interviewed, 16.9\% indicated that they had been bitten by an animal inside their home, $49 \cdot 4 \%$ by an animal at a neighbor's house and $33.7 \%$ reported experiencing a bite while on 
Table 2. Knowledge of rabies transmission and prevention of community members and healthcare professionals, Pétionville, Haiti, 2013

\begin{tabular}{|c|c|c|c|c|}
\hline \multirow[b]{2}{*}{ Rabies knowledge } & \multicolumn{2}{|c|}{$\begin{array}{l}\text { Community members } \\
(N=550)\end{array}$} & \multicolumn{2}{|c|}{$\begin{array}{l}\text { Healthcare } \\
\text { professionals }(N=106)\end{array}$} \\
\hline & $n$ & $\%$ & $n$ & $\%$ \\
\hline \multicolumn{5}{|l|}{ What animals can transmit rabies?* } \\
\hline Dog & 468 & $85 \cdot 1$ & 104 & $98 \cdot 1$ \\
\hline Cats & 163 & $29 \cdot 6$ & 75 & $70 \cdot 8$ \\
\hline Other (bats, mongoose) & 8 & $1 \cdot 5$ & 45 & $42 \cdot 5$ \\
\hline \multicolumn{5}{|l|}{ In what ways can rabies be transmitted to people?* } \\
\hline Bite from an animal & 416 & $75 \cdot 6$ & 78 & $73 \cdot 6$ \\
\hline Contact with saliva on open wounds & 10 & $1 \cdot 8$ & 21 & $19 \cdot 8$ \\
\hline Consumption of raw meat from rabid animals & 3 & 0.5 & 14 & $13 \cdot 2$ \\
\hline Don't know/No answer provided & 110 & $20 \cdot 0$ & 5 & $4 \cdot 7$ \\
\hline \multicolumn{5}{|c|}{ Can post-bite vaccination prevent a person from developing rabies? } \\
\hline Yes & 394 & $71 \cdot 6$ & 91 & 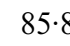 \\
\hline No & 113 & $20 \cdot 5$ & 15 & $14 \cdot 2$ \\
\hline Don’t know & 43 & $7 \cdot 8$ & 0 & 0 \\
\hline \multicolumn{5}{|c|}{ Do you know where to go to receive rabies vaccination if bitten by a suspected rabid animal? } \\
\hline Yes & 48 & $8 \cdot 7$ & - & - \\
\hline No & 502 & $91 \cdot 3$ & - & - \\
\hline \multicolumn{5}{|c|}{ Can a person with rabies be cured after symptom onset? } \\
\hline Yes & 301 & $54 \cdot 7$ & 52 & $49 \cdot 1$ \\
\hline No & 87 & $15 \cdot 8$ & 42 & $39 \cdot 6$ \\
\hline Don’t know & 162 & $29 \cdot 5$ & 12 & $11 \cdot 3$ \\
\hline \multicolumn{5}{|c|}{ Is vaccination of pets important for preventing human disease? } \\
\hline Yes & 437 & $79 \cdot 5$ & 104 & $98 \cdot 1$ \\
\hline No & 51 & $9 \cdot 3$ & 2 & 1.9 \\
\hline Don’t know & 62 & $11 \cdot 3$ & 0 & 0 \\
\hline \multicolumn{5}{|c|}{ Can a person with rabies transmit the disease to other people? } \\
\hline Yes & - & - & 48 & $45 \cdot 3$ \\
\hline No & - & - & 48 & $45 \cdot 3$ \\
\hline Don't know & - & - & 10 & $9 \cdot 4$ \\
\hline \multicolumn{5}{|c|}{ Should anyone with a bite from a suspected rabid animal be considered for rabies vaccination? } \\
\hline Yes & - & - & 91 & $85 \cdot 8$ \\
\hline No & - & - & 15 & $14 \cdot 2$ \\
\hline \multicolumn{5}{|c|}{ Does your institution have a protocol to guide in the treatment of bite victims? } \\
\hline Yes & - & - & 13 & $12 \cdot 3$ \\
\hline No & - & - & 93 & $87 \cdot 7$ \\
\hline \multicolumn{5}{|c|}{ Do you know where to obtain rabies vaccine for a bite victim? } \\
\hline Yes & - & - & 24 & $22 \cdot 6$ \\
\hline No & - & - & 82 & $77 \cdot 4$ \\
\hline
\end{tabular}

* Multiple responses allowed, totals may not add up to $100 \%$.

the street. The most common bite sites were lower extremities (84\%), followed by upper limbs $(11 \cdot 6 \%)$.

\section{HCPs}

A total of 165 HCPs were approached for this survey, of which 106 consented (response rate 64.2\%). The average age was 37 (range 23-72) years, and females represented $85.8 \%$ of respondents. Nurses comprised $67 \cdot 9 \%$ of respondents and doctors $32 \cdot 1 \%$ (Table 1 ).
Just over $98 \%$ of HCPs correctly identified dogs as the main transmitter of rabies virus in Haiti (Table 1). Cats were recognized as a risk for transmission by $70.8 \%$ of HCPs, and bats and mongooses by $42 \cdot 5 \%$. Bites were reported as a method of transmission by $73.6 \%$ of HCPs and direct contact the animal's saliva with mucous membranes or unhealed wounds was reported by $19 \cdot 8 \%$. Only $4.7 \%$ of $\mathrm{HCPs}$ were unaware of how rabies is transmitted. 
Table 3. Attitudes and practices towards bite events of community members, Pétionville, Haiti, 2013

\begin{tabular}{|c|c|c|c|c|c|}
\hline \multicolumn{3}{|l|}{$\begin{array}{l}\text { Attitudes towards bites from suspected rabid animals } \\
(N=550)\end{array}$} & \multicolumn{3}{|l|}{$\begin{array}{l}\text { Practices of persons bitten by a suspected rabid animal } \\
(N=172)\end{array}$} \\
\hline & $n$ & $\%$ & & $n$ & $\%$ \\
\hline $\begin{array}{l}\text { What would you do if bitten by a suspected } \\
\text { rabid animal?* }\end{array}$ & & & $\begin{array}{l}\text { What did you do after being bitten by the } \\
\text { suspected rabid animal?* }\end{array}$ & & \\
\hline Nothing & 3 & $0 \cdot 5$ & Nothing & 63 & $36 \cdot 6$ \\
\hline Wash the wound with soap and water & 33 & $6 \cdot 0$ & Washed the wound with soap and water & 14 & $8 \cdot 1$ \\
\hline Seek help in a clinic or hospital & 499 & $90 \cdot 7$ & Sought help in a clinic or hospital & 63 & $36 \cdot 6$ \\
\hline Self-administer antibiotics & 3 & $0 \cdot 5$ & Self-administered antibiotics & 1 & $0 \cdot 6$ \\
\hline Visit a traditional healer & 0 & $0 \cdot 0$ & Visited a traditional healer & 6 & $3 \cdot 5$ \\
\hline Don't know/Declined to answer & 20 & $3 \cdot 6$ & Don't know/Declined to answer & 25 & $14 \cdot 5$ \\
\hline $\begin{array}{l}\text { What would you do with an animal that had } \\
\text { bitten you or a family member?* }\end{array}$ & & & $\begin{array}{l}\text { What did you do with the animal that had } \\
\text { bitten you?* }\end{array}$ & & \\
\hline Nothing & 55 & $10 \cdot 0$ & Nothing & 138 & $80 \cdot 2$ \\
\hline $\begin{array}{l}\text { Observe the animal for } 14 \text { days for signs of } \\
\text { illness }\end{array}$ & 44 & $8 \cdot 0$ & $\begin{array}{l}\text { Observed the animal for } 14 \text { days for signs of } \\
\text { illness }\end{array}$ & 15 & $8 \cdot 7$ \\
\hline $\begin{array}{l}\text { Determine the rabies vaccination status of the } \\
\text { animal }\end{array}$ & 41 & $7 \cdot 5$ & $\begin{array}{l}\text { Determined the rabies vaccination status of the } \\
\text { animal }\end{array}$ & 2 & $1 \cdot 2$ \\
\hline Kill the animal & 256 & $46 \cdot 5$ & Killed the animal & 28 & $16 \cdot 3$ \\
\hline $\begin{array}{l}\text { Take the animal to a veterinarian for rabies } \\
\text { assessment }\end{array}$ & 73 & $13 \cdot 3$ & $\begin{array}{l}\text { Took the animal to a veterinarian for rabies } \\
\text { assessment }\end{array}$ & 3 & $1 \cdot 7$ \\
\hline \multirow[t]{5}{*}{ Don't know/Declined to answer } & 81 & $14 \cdot 7$ & & - & - \\
\hline & & & Did you receive rabies vaccination after the bite? & & \\
\hline & & & Yes & 54 & $31 \cdot 4$ \\
\hline & & & No & 110 & $64 \cdot 0$ \\
\hline & & & Don't know & 8 & $4 \cdot 7$ \\
\hline
\end{tabular}

* Multiple responses allowed, totals may not add up to $100 \%$.

Table 4. Annual and lifetime dog-bite incidence in community members, Pétionville, Haiti 2013

\begin{tabular}{llllll}
\hline \hline & $\begin{array}{l}\text { Community } \\
\text { respondents }(N)\end{array}$ & Life-years* & $\begin{array}{l}\text { Primary bites } \\
\text { reported }(N)\end{array}$ & $\begin{array}{l}\text { Lifetime } \\
\text { bite rate } \dagger\end{array}$ & $\begin{array}{l}\text { Annual bite incidence rate } \\
\text { (bites/100 life-years) } \$ \S\end{array}$ \\
\hline Age group, years & & & & & \\
$18-29$ & 266 & 6251 & 80 & $30 \cdot 0 \%$ & $1 \cdot 28$ \\
$30-39$ & 121 & $4174 \cdot 5$ & 43 & $35 \cdot 5 \%$ & $1 \cdot 03$ \\
$40-49$ & 66 & 2937 & 27 & $40 \cdot 9 \%$ & $0 \cdot 92$ \\
$50-59$ & 50 & 2720 & 18 & $36 \cdot 0 \%$ & $0 \cdot 66$ \\
$\geqslant 60$ & 47 & $3031 \cdot 5$ & 4 & $8 \cdot 5 \%$ & $0 \cdot 13$ \\
Sex & & & & $33 \cdot 9 \%$ & $0 \cdot 97$ \\
$\quad$ Male & 239 & 8365 & 81 & $29 \cdot 3 \%$ & $0 \cdot 84$ \\
$\quad$ Female & 311 & 10885 & 91 & $31 \cdot 3 \%$ & $0 \cdot 90$ \\
Total & 550 & 19114 & 172 & \\
\hline \hline
\end{tabular}

* Life-years were calculated as the product of the community respondents and the median of the age range.

$\dagger$ Lifetime bite rate was calculated as the quotient of the number of primary bites and the number of community respondents. $\$$ Annual bite incidence rate was calculated as the quotient of the primary bites and the life-years represented by the study participants. The incidence rate is given as the number of bite events/100 life-years.

$\S$ Because only primary bite events are represented in this table the lifetime bite rate and annual bite incidence rate represent a conservatively low estimate. 
Table 5. Characteristics of persons bitten by suspected rabid animal, Pétionville, Haiti, 2013

\begin{tabular}{|c|c|c|}
\hline & $n$ & $\%$ \\
\hline $\begin{array}{l}\text { Survey respondents ever bitten by a } \\
\text { suspected rabid animal }\end{array}$ & 172 of 550 & $31 \cdot 3$ \\
\hline Average number of bites (range) & $1 \cdot 1(1-3)$ & \\
\hline \multicolumn{3}{|l|}{$\begin{array}{l}\text { What animal was responsible for the } \\
\text { bite?* }\end{array}$} \\
\hline Dog & 161 & $93 \cdot 6$ \\
\hline Cat & 20 & $10 \cdot 8$ \\
\hline \multicolumn{3}{|l|}{ Age group (years) } \\
\hline $18-29$ & 80 & $46 \cdot 5$ \\
\hline $30-39$ & 43 & $25 \cdot 0$ \\
\hline $40-49$ & 27 & $15 \cdot 7$ \\
\hline $50-59$ & 18 & $10 \cdot 5$ \\
\hline$\geqslant 60$ & 4 & $2 \cdot 3$ \\
\hline \multicolumn{3}{|l|}{ Sex } \\
\hline Men & 81 & $47 \cdot 1$ \\
\hline Women & 91 & $52 \cdot 9$ \\
\hline \multicolumn{3}{|l|}{$\begin{array}{l}\text { Where were you when bitten by the } \\
\text { animal?* }\end{array}$} \\
\hline My home & 29 & $16 \cdot 9$ \\
\hline Neighbour's home & 85 & $49 \cdot 4$ \\
\hline On the street & 58 & $33 \cdot 7$ \\
\hline \multicolumn{3}{|l|}{$\begin{array}{l}\text { On what part of your body were you } \\
\text { bitten?* }\end{array}$} \\
\hline Lower limb & 145 & $84 \cdot 3$ \\
\hline Upper limb & 20 & $11 \cdot 6$ \\
\hline Chest & 6 & $3 \cdot 5$ \\
\hline Face & 2 & $1 \cdot 2$ \\
\hline
\end{tabular}

* Multiple responses allowed, totals may not add up to $100 \%$.

Only $14 \cdot 2 \%$ of HCPs reported having been trained regarding rabies prevention and bite management (Table 6). The majority $(87 \cdot 7 \%)$ of HCPs reported that their institutions did not have a protocol for the treatment of bite victims or rabies vaccination and $77 \cdot 4 \%$ were not aware of where to obtain rabies vaccine for bite victims (Table 2). When asked if people bitten by a suspected rabid animal should receive post-exposure prophylaxis, $85 \cdot 8 \%$ responded 'yes'. However, when asked what care they would recommend for a person with a suspected rabies exposure nearly $40 \%(39 \cdot 6 \%)$ of HCPs responded that they did not know. Wound washing was mentioned as a post-bite treatment option by $36 \%$ of HCPs and tetanus toxoid injection by $17.9 \%$. Rabies vaccination was only mentioned as a post-bite action by $2 \cdot 8 \%$ of HCPs (Tables 2 and 6 ).

\section{DISCUSSION}

This is the first assessment of rabies knowledge, attitudes, and practices in community members and medical professionals in Haiti. The study was conducted with three objectives: (i) to improve understanding of rabies exposure risks in Haiti, (ii) describe post-bite healthcare-seeking behaviours, and (iii) describe barriers to appropriate treatment. The timing of this study is unique, in that it describes these risks and behaviours prior to the development of national bite treatment and rabies vaccination guidelines. Based on the results of this study, recommendations were drafted in 2014 and HCP training began in early 2016 . Findings presented here address the study objectives as well as serve as a baseline for future studies by which the impact of the national guidelines can be measured.

\section{Rabies exposure risk}

Rabies is a zoonotic disease, and in Haiti it is primarily spread through the bite of an infected dog [8]. Therefore, two conditions must be satisfied for a rabies exposure to occur: a rabid $\operatorname{dog}$ and a bite event. The probabilities of these two events occurring is the basis for many probabilistic rabies burden models [2]. A 2015 surveillance publication reported that the rate of rabies in biting dogs was $7 \%$; however, at the time of this report the community bite rate was not known [9]. This survey reports an annual bite rate of $0.9 \%$ (a comparable figure to what has been reported in other developing countries) [10-13]. The annual bite rate was highest in the 18-29 years age group and declined with each following age group (Table 4). Bite incidence data for persons aged $<18$ years was not collected; however, the trend observed here is consistent with WHO published literature which equates a higher bite risk in younger age groups [14]. One in three bites occurred on the street; these exposures likely represent a higher rabies risk due to higher rates of rabies transmission in free-roaming dogs $[9,15]$.

The bite rate reported here is over three times lower than a bite rate reported by Schildecker et al. in 2016 in which dog owners attending a Haitian vaccination clinic were assessed (3.1\% bite rate for dog owners) [16]. There are several likely explanations for the lower bite rate in the present study. First, this is a general community survey, whereas the previous study [16] focused only on dog owners, who may have more frequent contact with dogs and therefore increased risk for a bite event. Second, this survey asked for all bite events in the respondent's lifetime, which is prone to recall bias and may underestimate 
Table 6. Practices of healthcare professionals when treating bite wound victims, Pétionville, Haiti, April 2013

\begin{tabular}{|c|c|c|}
\hline Survey questions & $n$ & $\%$ \\
\hline \multicolumn{3}{|l|}{ Have you ever received training on rabies control and prevention? } \\
\hline Yes & 15 & $14 \cdot 2$ \\
\hline No/Unknown & 91 & $85 \cdot 8$ \\
\hline \multicolumn{3}{|l|}{ Do you need to alert local authorities when you treat a bite victim? } \\
\hline Yes & 101 & $95 \cdot 3$ \\
\hline No/Unknown & 5 & $4 \cdot 7$ \\
\hline \multicolumn{3}{|l|}{ Do you discuss rabies with patients seeking treatment for an animal bite? } \\
\hline Never & 39 & $36 \cdot 8$ \\
\hline Sometimes & 53 & $50 \cdot 0$ \\
\hline Often & 9 & $8 \cdot 5$ \\
\hline Almost always & 5 & $4 \cdot 7$ \\
\hline \multicolumn{3}{|c|}{ What treatment do you recommend to patients bitten by an animal suspected of having rabies?* } \\
\hline None & 0 & 0 \\
\hline Immediately wash the wound with soap and water & 36 & $34 \cdot 0$ \\
\hline Administer a tetanus vaccine & 19 & $17 \cdot 9$ \\
\hline Administer antibiotic treatment & 6 & $5 \cdot 7$ \\
\hline Provide rabies post-exposure prophylaxis & 3 & $2 \cdot 8$ \\
\hline Don't know/Declined to answer & 42 & $39 \cdot 6$ \\
\hline \multicolumn{3}{|c|}{$\begin{array}{l}\text { What do you recommend to patients bitten by unfamiliar animals when your institution does not have rabies } \\
\text { vaccine in supply?* }\end{array}$} \\
\hline Nothing & 1 & $0 \cdot 9$ \\
\hline Tell the patient to return home & 1 & $0 \cdot 9$ \\
\hline Refer the patient to another centre where vaccine is available & 63 & $59 \cdot 4$ \\
\hline Call another institution to see if the vaccine is available & 11 & $10 \cdot 4$ \\
\hline Alert the health authorities in the region & 13 & $12 \cdot 3$ \\
\hline Don't know & 21 & $19 \cdot 8$ \\
\hline \multicolumn{3}{|l|}{ What do you recommend bite victims do with the animal which has bitten them?* } \\
\hline Observe the animal for at least 14 days & 73 & $68 \cdot 9$ \\
\hline Check if the animal has been vaccinated against rabies & 14 & $13 \cdot 2$ \\
\hline Kill the biting animal & 2 & 1.9 \\
\hline Take the animal to the veterinarian for a health assessment & 64 & $60 \cdot 4$ \\
\hline Don't know & 7 & $6 \cdot 6$ \\
\hline \multicolumn{3}{|l|}{ When should a person be given rabies vaccine?* } \\
\hline If the animal was confirmed to have rabies & 34 & $32 \cdot 1$ \\
\hline If the biting animal cannot be located or was unfamiliar to the bite victim & 19 & $17 \cdot 9$ \\
\hline If the biting animal died or was killed shortly after the bite & 21 & $19 \cdot 8$ \\
\hline If saliva made contact with broken skin or a mucous membrane (i.e. a bite) & 15 & $14 \cdot 2$ \\
\hline Don’t know & 39 & $36 \cdot 8$ \\
\hline
\end{tabular}

* Multiple responses allowed, totals may not add up to $100 \%$.

the true bite rate. Last, the bite rate is likely to be higher in children aged $<18$ years, which was not addressed in this study. The findings reported here, when considering Schildecker et al.'s findings, support the view that the dog bite rate in Haiti is not static and likely dependent upon dog ownership and the community in which an individual resides. The bite rate reported here is likely an underestimate, but potentially less biased than the population assessed by Schildecker et al. [16]. Therefore, utilizing the generalized community bite rate provided by this study is probably most appropriate for probabilistic modelling of rabies burden. However, more complex burden efforts should take into consideration that the risk for bites may be higher in certain populations.

\section{Healthcare-seeking behaviours}

Rabies is a preventable disease when appropriate postbite care is provided. Therefore, even in the face of a high risk for rabies exposure in Haiti, disease can be mitigated through appropriate healthcare-seeking behaviour and wound treatment. Unfortunately, findings from this study paint a bleak picture of 
healthcare-seeking behaviour in dog-bite victims. While nine out of ten individuals surveyed reported that they would seek medical care if they were bitten by an animal, in practice, fewer than four in ten people sought medical care after being bitten. Pétionville is one of the wealthiest communities within Haiti and, as expected, our study population had a household income over three times the national average [6]. Presumably, higher income families and communities have increased access to healthcare. Therefore, postbite healthcare-seeking behaviours are likely to be even lower in many parts of Haiti, and figures presented here represent a 'best-case scenario'.

Knowledge of rabies did not appear to be the primary reason for the observed low healthcare-seeking behaviours. Most respondents (85.1\%) knew that rabies is transmitted by dogs, via a bite $(75 \cdot 1 \%)$, and that rabies is preventable by vaccination $(71 \cdot 6 \%)$. But there were several educational deficits noted; few people recognized that washing the wound with soap and water can reduce the risk of rabies and only $15.8 \%$ of persons knew that rabies is fatal after symptom onset. These represent potential areas to engage communities through educational campaigns. However, healthcare outreach can be particularly difficult in developing world settings, where literacy and education levels are frequently encountered barriers $[10,17,18]$. In Haiti only $61 \%$ of the population is literate, compared to $92 \%$ in other Latin American countries, and only $10 \%$ of Haitians have access to the internet [6, 19]. Educational campaigns that utilize printed materials in combination with verbal engagement (i.e. radio) in lieu of more technologically advanced communication mediums may be more successful in reaching community members in Haiti. Integration of rabies prevention and control messaging into school curriculums may also be a successful strategy, as literacy rates may be higher in primaryand secondary-school children.

While healthcare-seeking behaviours were low, data suggests that when a person sought medical care they were very likely to receive rabies vaccination; 54 of 63 bite victims that sought medical care self-reported that they received rabies vaccination. However, other data from this study conflict with this self-reported vaccination rate. For example, only $23 \%$ of HCPs even knew where to obtain rabies vaccine and only $2 \cdot 8 \%$ listed rabies vaccination as a standard component of postbite care. Survey methodology utilized open-ended questions which can prevent the respondent from falsely identifying information that is revealed by the interviewer. Unfortunately, this design limits our ability to state that HCPs would not have provided rabies vaccine to the hypothetical bite victim. When asked directly if rabies vaccine should be provided for persons bitten by a suspected rabid dog, nine of ten HCPs answered affirmatively. In this respect, the HCP inconsistency regarding rabies vaccination is likely due to survey design.

Given the apparent difficulty in locating rabies vaccine in Haiti and questionable provider response rate for administering the vaccine, it is difficult to imagine that rabies vaccine administration is as high as the self-reported rate identified here. It may be likely that persons who sought medical care were unaware of what they had received; a probable scenario, as tetanus and antibiotics were much more frequently reported by HCPs as standards of bite treatment compared to rabies vaccine. Anecdotally, it is common for bite victims in Haiti to be unaware of what they were treated with; often confusing a one-time tetanus shot with the rabies vaccine. Furthermore, this study did not assess how many doses nor the dosing schedule that the bite victims adhered to, both are critical to prevent development of rabies. A more robust method for describing rabies vaccination practices and adherence is warranted, such as a prospective healthcarebased study and a systematic evaluation of the rabies vaccine distribution system.

Perhaps the most pronounced barrier to rabies prevention identified in this study pertained to HCP training; fewer than $15 \%$ of HCPs reported that they had received training regarding rabies prevention. At the time of this survey in 2013 Haiti had no national recommendations for the treatment of bite wounds nor recommendations for the prescription of rabies vaccination. Probably a reflection of this lack of recommendations and training, $50 \%$ of HCPs thought that rabies was treatable after symptom onset and $40 \%$ stated that they did not know what care they should provide to a bite victim. In 2014 preliminary findings from this study were shared with MSPP, and in response, PAHO assisted in the development of a healthcare provider education programme on rabies. As of 2016, this training programme had been implemented in selected areas, but had not yet been nationally disseminated. The impact of these guidelines should be measured in the future and compared to the findings from this study.

Haiti has a fragmented healthcare delivery system, and this impacts the distribution and availability of rabies vaccine. Human rabies vaccine is typically 
donated by international governments to MSPP, which distributes the vaccine to only 16 health centres, out of more than 116 sentinel hospitals [4]. These 16 health centres often report being out of stock of the vaccine, and national shortages have occurred over the past 5 years. Vaccine can be procured from some private pharmacies at a cost of 25 USD per dose, the equivalent of 2 months wages for a complete five-dose course for the average Haitian family. Even with improvements in bite treatment training, shortages of vaccines and deficiencies in vaccine distribution may still prohibit appropriate vaccination of bite victims. Therefore, evaluation of existing vaccine distribution channels and enhancing rabies vaccine distribution should be considered.

\section{Rabies prevention and animal vaccination}

Many survey respondents recognized the importance of canine rabies vaccination in disease control. However, in practice, only $35.9 \%$ of community respondents' dogs were vaccinated against rabies (an even lower vaccination rate was observed in dogs owned by HCPs). This represents a gap in knowledge and practice of animal rabies vaccination, and several factors may be responsible. Haiti has very limited veterinary capacity with fewer than 50 veterinarians for the entire country's $10 \cdot 5$ million people; therefore, access to routine animal care, including rabies vaccination, is unlikely for many pet owners. After the 2010 earthquake, access to medical supplies, including rabies vaccines for animals, declined sharply. Currently, for most Haitians, animal rabies vaccine is only available during government mass vaccination campaigns. When these campaigns are not held, animal rabies vaccine may be almost impossible to procure. Furthermore, the average Haitian survives on less than 3 USD per day; therefore, despite awareness of the benefits of rabies vaccination, payment for veterinary services may not be feasible [6]. The average income of our study population was three times the Haitian national average, so cost of vaccine may not have driven the low vaccination rates in this community, rather access to the vaccines may be an important factor. Increasing the frequency and accessibility of dog rabies vaccination programmes, in a manner which considers the high poverty levels in Haiti, is probably needed to see increases in dog vaccination coverage.

This study has several limitations. First, it was focused in one commune within the capital city, Port-au-Prince, and therefore may not be representative of all Haitian communities. Pétionville is one of the wealthier communes in Haiti, therefore access to education and health services may be better compared to the majority of Haitians. In that respect, the results from this survey may represent a 'best-case scenario'. In addition, the survey of HCPs was a convenience sample, and therefore the HCPs interviewed may not be representative of all HCPs in Pétionville.

In conclusion, this study identified that in community members and HCPs in a community at a relatively high socioeconomic level for Haiti, large disconnects exist between rabies knowledge and practices. As a promising sign, after results of this survey were reported to MSPP, national bite treatment guidelines were developed and a healthcare provider education programme was implemented in select communities. These training programmes for HCPs should be evaluated and, if effective, expanded. Difficulties in access to both human and animal rabies vaccination was evident for this study population, and efforts should be made to make these vaccines more accessible within the country. With the high rate of rabies exposure in Haiti, an educated healthcare workforce and population will be necessary to ensure appropriate treatment for persons exposed to rabid animals.

\section{SUPPLEMENTARY MATERIAL}

For supplementary material accompanying this paper visit https://doi.org/10.1017/S0950268816003125.

\section{ACKNOWLEDGEMENTS}

The views presented in this article are those of the authors and do not necessarily represent the opinions of their affiliated institutions.

\section{DECLARATION OF INTEREST}

None.

\section{REFERENCES}

1. Fooks AR, et al. Current status of rabies and prospects for elimination. Lancet 2014; 384: 1389-1399.

2. Hampson K, et al. Estimating the global burden of endemic canine rabies. PLoS Neglected Tropical Diseases 2015; 9: e0003709.

3. Vigilato MA, et al. Progress towards eliminating canine rabies: policies and perspectives from Latin 
America and the Caribbean. Philosophical Transactions of the Royal Society of London, Series B 2013; 368: 20120143.

4. Millien MF, et al. Control of dog mediated human rabies in haiti: no time to spare. PLoS Neglected Tropical Diseases 2015; 9: e0003806.

5. Lembo T, et al. The feasibility of canine rabies elimination in Africa: dispelling doubts with data. PLoS Neglected Tropical Diseases 2010; 4: e626.

6. CIA. The World Factbook 2013-14. Washington DC: CIA, 2013.

7. Lavrakas PJ (ed.). Encyclopedia of Survey Research Methods. Thousand Oaks, United States: Sage Publications Inc., 2008, p. 1072.

8. Vigilato MA, et al. Rabies update for Latin America and the Caribbean. Emerging Infectious Diseases 2013; 19: $678-679$.

9. Wallace RM, et al. Establishment of a canine rabies burden in Haiti through the implementation of a novel surveillance program. PLoS Neglected Tropical Diseases 2015; 9: e0004245.

10. Mucheru GM, Kikuvi GM, Amwayi SA. Knowledge and practices towards rabies and determinants of dog rabies vaccination in households: a cross sectional study in an area with high dog bite incidents in Kakamega County, Kenya, 2013. Pan African Medical Journal 2014; 19: 255.
11. Chang YF, et al. Dog bite incidence in the city of Pittsburgh: a capture-recapture approach. American Journal of Public Health 1997; 87: 1703-1705.

12. Chomel BB, Trotignon J. Epidemiologic surveys of dog and cat bites in the Lyon area, France. European Journal of Epidemiology 1992; 8: 619-624.

13. Tenzin et al. Dog bites in humans and estimating human rabies mortality in rabies endemic areas of Bhutan. PLoS Neglected Tropical Diseases 2011; 5: e1391.

14. World Health Organization. WHO Expert Consultation on Rabies. Second report. World Health Organization Technical Report Series, 2013; 982: 1-139.

15. Salem DJ. The State of the Animals, vol. IV. Portland, OR: Book News Inc., 2007, p. 238.

16. Schildecker $\mathbf{S}$, et al. Dog ecology and barriers to canine rabies control in the Republic of Haiti, 2014-2015. Transboundary Emerging Diseases. Published online: 17 June 2016. doi:10.1111/tbed.12531.

17. Kalichman SC, et al. Health literacy and health-related knowledge among persons living with HIV/AIDS. American Journal of Preventive Medicine 2000; 18: 325-331.

18. Schillinger D. Literacy and health communication: reversing the 'inverse care law'. American Journal of Bioethics 2007; 7: 15-8; discussion W1-2.

19. World Bank. World development indicators, 2015 (http://data.worldbank.org/country/haiti\#cp_wdi). Accessed 25 September 2015. 